\title{
A LUTA POR TERRA E ÁGUA NO QUILOMBO DE ACAUÃ NO RIO GRANDE DO NORTE, BRASIL
}

\section{LA LUCHA POR TIERRA Y AGUA EN EL QUILOMBO DE ACAUÃ EN RIO GRANDE DO NORTE, BRASIL}

\author{
Camila da Silva Pereira \\ Faculdade de Filosofia Dom Aureliano Matos. Universidade Estadual do Ceará. FAFIDAM - UECE, \\ Limoeiro do Norte, CE, Brasil \\ mila.pereira@uece.br
}

\section{Resumo}

A invisibilização das comunidades quilombolas por meio de discursos e práticas sociais, políticas e culturais, vem, ao longo de toda a história de luta dessas comunidades, ameaçando a conquista de direitos territoriais, sobretudo o direito à terra. No Brasil, entre 2004 e 2018, sob a alegação da inconstitucionalidade do Decreto 4.887/2003 que regulamenta os procedimentos de titulação da terra, a Ação Direta de Inconstitucionalidade (ADI 3.239/2004) incentivou disputas territoriais e conflitos entre comunidades quilombolas e proprietários de terra, a exemplo da comunidade quilombola Acauã situada no município de Poço Branco no estado do Rio Grande do Norte, Brasil. Este trabalho resulta da pesquisa de doutorado em Geografia pela Universidade Federal do Ceará, Fortaleza, Brasil, encerrada em junho de 2019. Realizamos levantamento bibliográfico, coleta de dados secundários nos sites do Incra e da Fundação Cultural Palmares, registros fotográficos, mapeamento territorial e entrevista semiestruturada com liderança quilombola na comunidade. Os conflitos enfrentados pelos quilombolas de Acauã frente às formas de exploração da terra e diante das estratégias de privá-los de seu direito principal para a sobrevivência, expressam a realidade de muitas outras comunidades quilombolas do Brasil que estão em área de expansão do capital e que embora tenham assegurados legalmente seus direitos, estes não são garantidos em meio às investidas dos agentes capitalistas no espaço e pela burocracia das ações por parte do Estado.

Palavras-chave: Quilombolas. Terra. Território. Conflitos territoriais. Direitos territoriais.

\section{Resumen}

La invisibilidad de las comunidades quilombolas a través de discursos y prácticas sociales, políticas y culturales, ha amenazado, a lo largo de la historia de lucha de estas comunidades, la conquista de los derechos territoriales, especialmente el derecho a la tierra. En Brasil, entre 2004 y 2018, bajo el alegato de inconstitucionalidad del Decreto 4.887 / 2003 que regula los procedimientos de titulación de tierras, la Acción Directa de Inconstitucionalidad (ADI 3.239/2004) alentó disputas territoriales y conflictos entre comunidades quilombolas y terratenientes, como la comunidad quilombola Acauã 
ubicada en el municipio de Poço Branco en el estado de Rio Grande do Norte, Brasil. Este trabajo es el resultado de la investigación doctoral en Geografía de la Universidad Federal de Ceará, Fortaleza, Brasil, que finalizó en junio de 2019. Realizamos investigación bibliográfica, recopilación de datos secundarios en los sitios web de Incra y Fundação Cultural Palmares, registros fotográficos, mapeo territorial y entrevista semiestructurada com liderazgo quilombola em la comunidad. Los conflictos que enfrentan los quilombolas en Acauã frente a las formas de exploración de tierras y dadas las estrategias para privarlos de su derecho principal a la supervivencia, expresan la realidad de muchas otras comunidades quilombolas en Brasil que se encuentran en una zona de expansión de capital y que si bien han garantizado legalmente sus derechos, estos no están garantizados en medio de los ataques de los agentes capitalistas en el espacio y la burocracia de las acciones del Estado.

Palabras-clave: Quilombolas. Tierra. Territorio. Conflictos territoriales. Derechos territoriales.

\section{Introdução}

A invisibilidade atribuída às comunidades quilombolas produzida pelos discursos de negação de suas organizações territoriais e dos seus direitos coletivos é fruto do processo de subjugação desses povos às classes dominantes que, desde a inserção legal de suas demandas na Constituição Federal de 1988, regulamentadas pelo Decreto 4.887/2003 no Governo de Luís Inácio Lula da Silva, utilizam meios para retardar a efetivação dos direitos dessas comunidades, entre os quais o principal é a terra coletiva.

Em 2004, com a alegação da inconstitucionalidade do Decreto 4.887 pela Ação Direta de Inconstitucionalidade (ADI 3.239/2004), as comunidades quilombolas de todo o Brasil enfrentaram uma das principais tentativas de retirada do seu direito à terra. Os anos subsequentes nos quais a ADI esteve em processo de votação, sendo encerrada em 2018 com maioria de votos contra à referida ação, comunidades de todo o Brasil continuaram a enfrentar conflitos por terra sob a alegação de que não tinham esse direito, visto que a autodeclaração identitária era uma das inconsistências apontadas pela ADI, como foi o caso da comunidade Acauã situada no município de Poço Branco a $63 \mathrm{~km}$ da capital do estado do Rio Grande do Norte, Natal, Brasil.

No entanto, o marco principal da luta da comunidade por terra e água se deu com a construção da barragem Engenheiro José Batista do Rego Pereira, conhecida também como açude Poço Branco entre 1959 e 1968. Nesse processo, o rio Ceará- 
Mirim teve seu nível aumentado, significativamente, ocasionando a realocação das famílias que viviam às margens, como os povoados denominados de Contador e a antiga Cunhã Velha como era chamada, que além de perderem as terras onde viviam e plantavam, tiveram dificuldades de sobreviver no novo local de moradia, principalmente, pela limitação no uso da água do reservatório e pelas disputas por terra com fazendeiros e posseiros que se instalaram após a construção da barragem.

Este trabalho resulta da pesquisa de doutorado em Geografia pela Universidade Federal do Ceará, Fortaleza, Brasil, encerrada em junho de 2019. Portanto, para o aprofundamento da análise realizou-se pesquisa bibliográfica a partir de autores como: Fernandes et al (2017) e Almeida (2011) para discutir os conflitos no campo, a luta por terra e os direitos quilombolas; Arguedas (2015) e Valle (2006) para entender o processo de formação da comunidade Acauã e os conflitos decorrentes das formas de uso do território por agentes capitalistas e Haesbaert (2005 e 2010) para discutir o conceito de território, os processos de desterritorialização e reterritorialização, bem como as relações de poder que determinam o uso e o ordenamento do território.

Realizou-se, também, a coleta de dados secundários no site do Instituto Nacional de Colonização e Reforma Agrária (Incra) e da Fundação Cultural Palmares (FCP), além de pesquisa documental em arquivos do Incra - RN e no relatório antropológico da comunidade Acauã. Realizou-se entrevista semiestruturada com a ex-liderança da comunidade, registros fotográficos e um mapeamento das estruturas e das áreas de conflitos com proprietários e posseiros presentes no território de Acauã.

Os conflitos mais recentes enfrentados pela comunidade Acauã datam de 2004, ano em que é oficialmente reconhecida pela FCP e passa a ter processo de titulação aberto no Incra. Essas tensões estimularam dois movimentos: de um lado, as relações dos grupos se fragmentaram pela migração de moradores que se viram ameaçados; de outro, a comunidade encontrou caminhos de fortalecimento em defesa do território do qual já foram expropriados.

O texto está organizado em duas sessões. Na primeira discute-se no recorte da década de 1930 até os dias atuais, alguns dos principais marcos da conquista de direitos pelas comunidades quilombolas em todo o Brasil, principalmente a partir da atuação de organizações como a Frente Negra Brasileira e o Movimento Negro Unificado frente às estratégias de desmonte e morosidade na efetivação de direitos por parte do Estado. Na 
segunda parte verticaliza-se a análise para o contexto de ameaças ao direito de titulação do território de Acauã que no cenário potiguar e em estados circunvizinhos obteve repercussão considerável, ocasionando o movimento chamado "Somos todos Acauã", o que contribuiu para que o processo movido contra a comunidade, utilizando a ADI como justificativa para negar-lhes seu direito, fosse estancado e, posteriormente, encerrado a favor do direito da comunidade.

\section{Dos direitos conquistados aos direitos ameaçados: resistência quilombola e os arranjos burocráticos para a titulação das terras}

Os quilombos no Brasil, assim denominados a partir de 1559 foram, inicialmente, conhecidos como mocambos. Formados, majoritariamente, por negros oriundos de processos de fuga, mas também por outros grupos étnicos sob situação de exploração, foram organizações presentes em quase toda a América Latina e em alguns países da América do Norte que adotaram o regime de escravidão (GOMES, 2015). As especificidades dos processos de formação e as diversas nomenclaturas atribuídas, ao longo do tempo, a essas organizações de resistência ao regime vigente e aos desdobramentos dessas imposições, não mais permitem restringir o seu entendimento às visões herdadas da conceituação colonialista do Conselho Ultramarino de 1740 ao Rei de Portugal, que definia as organizações quilombolas como "toda habitação de negros fugidos que passem de cinco, em parte despovoada, ainda que não tenham ranchos levantados nem se achem pilões neles" .

No lapso de tempo que separa o regime escravocrata e sua a abolição oficial, inúmeras foram as estratégias de invalidar e invisibilizar a luta dos povos quilombolas, que diante da construção de uma sociedade aristocrata e burguesa que deslocou socialmente o negro pela ideologia de inferioridade racial, também ocasionou o processo de negação da sua presença em colônias e estados, sobretudo, estruturadas pelas relações coronelistas. Assim, dos anos que sequenciaram a data oficial da abolição da escravidão no Brasil até meados de 1920, as identificações quilombolas, em todo o país, sofreram um processo de invisibilização pelo Estado sob as afirmações de que, passado o regime escravocrata não mais existiam os quilombos (FERNANDES, 2008).

\footnotetext{
${ }^{1}$ http://www.itcg.pr.gov.br/arquivos/File/Quilombos.pdf.
} 
Em se tratando desse processo no Rio Grande do Norte e em outros estados, sobretudo, do Nordeste, em que as identidades quilombolas foram encobertas pelas relações paternalistas e de compadrio ${ }^{2}$ que negavam a existência do escravismo, o movimento de invisibilização foi ainda mais reforçado pela justificativa da existência de um menor quantitativo de negros no estado, causando um processo tardio de oficialização dos movimentos sociais e instituições responsáveis pela mediação das suas demandas territoriais ${ }^{3}$.

Alguns dos principais marcos oficiais das lutas e conquistas de direitos dos povos quilombolas, a partir do apoio de organizações e movimentos no Brasil, datam do início dos anos de 1930 com a criação da Frente Negra Brasileira em meio à revolução de 30. A Frente Negra Brasileira inspirou a participação política de pessoas negras no movimento, abrindo representações em Pernambuco, Minas Gerais, Bahia, Rio Grande do Sul, entre outros (PEREIRA, 2008). Em meados de 1937 a Frente Negra Brasileira teve seu fim, transformando-se em partido político em meio a decretação do Estado Novo, mas o incentivo à construção de movimentos sociais em outros estados brasileiros acabou contribuindo para que as mobilizações do povo negro não cessassem em meio ao acentuado processo de crescimento da burguesia e do fortalecimento desta com o apoio do Estado.

De acordo com Pereira (2008) após o fim do Estado Novo, em meados de 1940, o Movimento Negro encontra novamente espaço para atuação, criando no Rio de Janeiro, em 1945, o Comitê Democrático Afro-brasileiro, com a intenção de adquirir voz na Assembleia Nacional Constituinte. Em seguida, na mesma década, surgem o Teatro Experimental do Negro e o Teatro Popular Brasileiro, ambos com o intuito de valorizar a cultura do povo negro na sociedade.

Em relação às conquistas do povo negro por meio da atuação do Movimento Negro, ainda não oficializado no início do século XX, destaca-se a promulgação da Lei Afonso Arinos - Lei 1.390/51, de 3 de julho de 1951 que incluía penalidades para as práticas preconceituosas em relação à raça e à cor. A Lei $n^{0} 7.437$, de 20 de dezembro de 1985 que penalizava as formas de preconceito contra raça, cor, sexo e estado civil e, por fim, a Lei 7.716, de 5 de janeiro de 1989, ambas criadas no governo de José Sarney,

\footnotetext{
2 Vide Woortmann, 1995 sobre compadrio e Chalhoub (2003) sobre paternalismo.

${ }^{3}$ Ver tese de doutorado da autora intitulada "Identidades (re)descobertas e a luta quilombola por direitos territoriais no estado do Rio Grande do Norte, Brasil" (2019).
} 
sendo esta última após a Constituição de 1988, determinando ser crime as práticas e discursos preconceituosos.

As lutas do Movimento Negro tiveram início na década de 1930, mas foi em 1970 que o movimento começa a se reestruturar, quando representantes de várias entidades se reuniram em resposta à discriminação racial sofrida por quatro garotos do time infantil de voleibol do Clube de Regatas Tietê e a prisão, tortura e morte de Robison Silveira da Luz, acusado de roubar frutas numa feira em São Paulo. Além desses episódios, o aumento dos casos de racismo e assassinatos de negros nas principais capitais do Brasil suscitou mobilizações para a criação de um movimento que fosse representativo nos debates sobre a discriminação racial de negros e, posteriormente, aliou-se à luta quilombola, mediando a reivindicação de suas demandas frente ao Estado. O Movimento Negro Unificado oficializou-se em 7 de julho de 1978 em meio à Ditadura Militar e culminou na criação do primeiro órgão público voltado para o apoio dos movimentos sociais afro-brasileiros em 1984, o Conselho de Participação e Desenvolvimento da Comunidade Negra (PEREIRA, 2008).

Especificamente em relação às comunidades quilombolas o principal direito adquirido ao longo dos anos até a promulgação da Constituição de 1988, foi o reconhecimento do direito ancestral à terra. Nos artigos 68 da Constituição, ficam determinados, respectivamente, que aos remanescentes das comunidades dos quilombos que estejam ocupando suas terras é reconhecida a propriedade definitiva, devendo o Estado emitir-lhes os títulos respectivos.

Os quilombos coloniais passaram a serem entendidos na perspectiva do que Fiabani (2008) chama de quilombos de hoje ou os novos quilombos. Tais territórios, embora sejam fundamentados a partir de características seculares, a exemplo das relações consanguíneas de parentesco e uma ancestralidade negra escravizada, apresentam uma dimensão territorial diferenciada dos quilombos coloniais em termos de organização, dinâmica territorial e modos de vida que, não somente se baseiam no trabalho familiar, mas se inserem na lógica de recriação do campesinato dentro do modo de produção capitalista.

Os novos quilombos, compreendendo a diversidade nas suas formas de organização, configuram-se por novas famílias descendentes de negros em luta pela libertação que, historicamente, buscam a autonomia sob os modos de vida em seus 
territórios. Os mecanismos de defesa de seus territórios se ressignificaram e há um processo contínuo de afirmação e busca por reconhecimento de seus direitos, historicamente, negados (ALMEIDA, 2011).

Alguns dos enfrentamentos jurídicos e burocráticos que vêm colocando em risco a manutenção dos direitos já adquiridos pelas comunidades quilombolas em todo o Brasil é a ADI 3.239/2004, ajuizada pelo Partido da Frente Liberal, atual Democratas. A ADI questionava e alegava a inconstitucionalidade do referido decreto que regulamenta o procedimento para identificação, reconhecimento, delimitação, demarcação e titulação das terras ocupadas por remanescentes quilombolas conforme o art. 68 do Ato das Disposições Constitucionais Transitórias da Constituição Federal de 1988.

Impetrada ao longo dos anos do governo do Partido dos Trabalhadores (PT), as principais alegações inclusas na ADI defendiam que o critério de autodeclaração de ser quilombola "fere" a Constituição, ao passo que o próprio interessado nas terras se reconhece quilombola. Diamantino (2016) ressalta que a Ação exige que os direitos constitucionais sejam assegurados unicamente para as comunidades que tenham processo de formação anterior à data da abolição oficial da escravidão. Isso configura uma tentativa que visa deslegitimar a luta quilombola e o histórico pós-abolição de expropriação da terra e dos direitos territoriais, visto que as formas de escravismo se mantiveram passado o regime de escravidão, a partir de outros mecanismos de opressão e dominância.

De acordo com a Comissão Pró-índio de São Paulo (2015) outra alegação da ADI é que o decreto é inconstitucional pela inexistência de lei que lhe confira validade, já que a Constituição não pode ser regulamentada por decreto. No entanto, essa prerrogativa não se fundamenta tendo em vista que o artigo 68 prevê a garantia de direitos fundamentais de aplicação imediata. O decreto somente regulamenta os trâmites da ação não necessitando de lei para a sua efetivação.

A votação da ADI foi iniciada em 2012 no Superior Tribunal Federal (STF) com o voto do ministro Antônio Cezar Peluso que acatou o pedido de abertura do processo de modo que os títulos emitidos até a presente data do Decreto 4.887 seriam considerados válidos. A votação foi interrompida a pedido da ministra Rosa Weber para revisão, reconhecendo a permanência dos critérios de avaliação para a titulação de terras quilombolas. 
Em dezembro de 2014 a ADI retornou a pauta do STF, mas foi novamente protelada. Em março de 2015 o STF retomou o julgamento tendo um novo pedido de revisão feito pelo ministro Dias Toffoli. Em 18 de outubro de 2017 a votação que iria ocorrer em Brasília foi novamente adiada. Somente em 08 de fevereiro de 2018 o STF reabriu a votação e por maioria de votos a favor, declarou-se a constitucionalidade do Decreto 4.887. Foram 8 votos contra a ADI, 2 votos pela sua aprovação parcial solicitando a sua revisão e 1 voto a favor (BRASIL, 2018).

No Rio Grande do Norte, a comunidade Acauã foi alvo dos questionamentos presentes na ADI, a partir da reabertura de uma ação por um fazendeiro local não satisfeito com o resultado de um processo ganho pela comunidade. A reabertura do processo causou mobilizações em todo o estado, visto que as demais comunidades se viram numa situação de risco de revisão de seus processos em tramitação ou já finalizados, o que culminou na audiência em defesa de Acauã idealizada pelo Conselho Estadual da Mulher (Conem), pela Rede de Mulheres Negras do Brasil e por uma quilombola de Acauã representante da Coeq - RN, sendo mediada pelo Deputado Estadual Fernando Mineiro do PT (CONAQ, 2017).

Ainda sobre ameaça ou retira direitos dos povos quilombolas, destacamos que desde 2014 os investimentos em políticas públicas para as comunidades quilombolas vêm sendo reduzidos. Dentre estes destacamos o Programa Territórios da Cidadania ${ }^{4}$, vinculado ao Ministério do Desenvolvimento Agrário (MDA). Em 2012 desenvolveu uma ação chamada: Projeto de Articulação e Acesso das Comunidades Quilombolas às Políticas Públicas de Desenvolvimento Rural nos Territórios da Cidadania, abrangendo 580 comunidades quilombolas em todo o Brasil, número aquém da quantidade de comunidades certificadas pela FCP, sendo que no Rio Grande do Norte somente constava comunidades do Território da Cidadania Seridó, onde está presente as comunidades Boa Vista dos Negros, Macambira e Negros do Riacho. Em relação as áreas indenizadas foram investidos pelo Programa, em 2008, R\$ 39.100.000,00 para a desapropriação de 625.361 ha de terras em todo o Brasil (BRASIL, MDA, 2008).

\footnotetext{
${ }^{4}$ Criado em 2008 no governo do Presidente Luís Inácio Lula da Silva com um total de 60 territórios, passando em 2009 para 120 territórios. O programa constitui uma estratégia de regionalização nos estados a partir dos critérios: menor IDH, maior concentração de agricultores familiares, assentamentos da Reforma Agrária, quilombolas, indígenas, maior número de beneficiários do Programa Bolsa Família e municípios com baixo dinamismo; abrange quilombolas, assentados, indígenas, pescadores, entre outros. No Rio Grande do Norte foram criados 6 territórios da cidadania: Açú-Mossoró, Alto Oeste, Mato Grande, Potengi, Seridó e Sertão do Apodi (MDA, 2008).
} 
A diminuição dos repasses para o Programa Territórios da cidadania entre 2014 e 2016 e a não existência de orçamento para suas ações entre 2017 a 2018, é apenas um exemplo do desmonte das políticas sociais destinadas a atender demandas básicas desses grupos. Com o golpe de 2016 que resultou no impeachment da então presidenta Dilma Rousseff e a posse do vice-presidente no Planalto, Michel Temer, iniciou-se uma série de mudanças nas pastas administrativas do governo, assim como reforçou-se a redução nas verbas para ações de diversas políticas públicas. No âmbito das políticas para os povos do campo e para as comunidades quilombolas as principais mudanças foram o fim do MDA e a transferência do Incra e as ações de reforma agrária e titulação dos territórios quilombolas para a Casa Civil.

O cenário de instabilidade e morosidade no andamento das ações de reforma agrária, que também envolvem as comunidades quilombolas, já se projetava durante o governo Dilma que, de acordo com Fernandes et al (2017), configurou um dos mais relapsos em termos de ações de reforma agrária presenciando o aumento do número de manifestações em todo o Brasil, estimuladas também pelo poder controlador das mídias. Além disso, a ampliação de entrada do capital no campo através de empresas do agronegócio e a expropriação e as ameaças aos povos do campo se legitima, com mais ênfase, no processo de transição do governo Michel Temer para o do atual presidente Jair Messias Bolsonaro, iniciado em 2019, que já nos primeiros dias de gestão implementou mudanças bruscas e obscuras em diversos setores administrativos do governo e, para as comunidades quilombolas e indígenas, direcionou as ações de demarcação e titulação das terras do Incra e da Funai para o Ministério da Agricultura, por meio da assinatura da Medida Provisória 870/20195.

Os riscos de perda ou o retardamento na garantia de direitos são previstos por órgãos e movimentos sociais, visto que o ministério responsável pelas ações de titulação dos territórios quilombolas, ainda não tem definido como irá tramitar as ações, além de ser conduzido por ex membros e simpatizantes da bancada ruralista no Congresso Nacional.

\footnotetext{
${ }^{5}$ Em maio de 2019, a emenda constitucional 426 de autoria do deputado federal Túlio Gadêlha (Partido Democrático Trabalhista - PDT) foi aprovada pela comissão mista da MP. O texto inclui a transferência da Funai para o Ministério da Justiça, que hoje está no Ministério da Mulher, da Família e dos Direitos Humanos, bem como que a demarcação das terras indígenas volte a ser atribuição da Funai. Embora ainda necessite passar pela Câmara dos Deputados e pelo Senado Federal, a aprovação do texto pela comissão já é considerada um avanço para a continuidade das ações para a garantia da demarcação das terras indígenas.
} 
No item a seguir, traçamos essa análise utilizando como estudo de caso a comunidade quilombola Acauã no município de Poço Branco - RN, que configura o quadro das 28 comunidades reconhecidas oficialmente no estado, entre as quais apresenta processo de titulação em estágio avançado no Incra, além de ter sido um dos territórios aonde ocorreu, ainda havendo vestígios, um dos conflitos mais expressivos nas últimas décadas, a luta pela água e pela terra.

\section{"Mexeu com uma, mexeu com todas": conflitos territoriais e resistências em Acauã}

Localizada a $63 \mathrm{~km}$ da capital do Rio Grande do Norte, Natal, Acauã está situada no município de Poço Branco na microrregião da Baixa Verde e, de acordo com o último censo do IBGE de 2010, apresentou população de 13.949 habitantes. A respeito do histórico de formação da comunidade de Acauã, os moradores elencam duas principais vertentes de entendimento, ambas com bastante imprecisão nos anos, mas estima-se que a comunidade se formou no final do século XIX. Inicialmente, as terras teriam sido ocupadas por José Acauã no lado direito do rio Ceará-Mirim, escravizado e fugitivo dos engenhos do baixo vale do Ceará- Mirim. Outra vertente é apontada pela memória genealógica sobre três irmãs (Ana, Benedita e Catarina). Ana e Catarina teriam se casado com os irmãos Joaquim Gomes e Sebastião Rodrigues dando início as relações de parentesco que deram origem à comunidade (VALLE, 2006, p. 133).

$\mathrm{Na}$ literatura e na história oral a respeito das comunidades quilombolas rurais, há sempre descontinuidades quando se trata de investigar os vínculos de ligação das comunidades quilombolas com um passado escravista, seja pela escassez ou inexistência de documentos que apontem tais fatos, ou pelas fragmentações existentes nas memórias dos grupos e segundo Bosi (2003) a memória e as histórias por ela resgatadas expressam as sensibilidades dos sujeitos em meio às suas contradições.

Assim como outros municípios brasileiros, Poço Branco construiu-se e desenvolveu-se às margens do Rio Ceará-Mirim, a partir do cultivo de lavouras de milho, feijão, mandioca, algodão e também com a criação de gado. A importância da água atravessa o histórico de formação de comunidades, cidades e municípios e, em muitos casos, protagoniza o cenário de disputas territoriais. No caso de Acauã, a água 
foi, ao longo de décadas, o principal elemento definidor de mudanças nas dinâmicas dos quilombolas da antiga Cunhã Velha e da atual comunidade de Acauã (VALLE, 2006).

A gestão dos recursos hídricos, especificamente, na região Nordeste esteve ligada às políticas desenvolvimentistas, alavancadas, a partir da década de 1950. Nesse período, em que a estiagem se prolongou na região até meados de 1958, diversas obras de construção de açudes e barragens foram encabeçadas, principalmente, para atender aos interesses de elites agrárias e políticas à época que visavam garantir aumento da produção com o uso controlado da água (ARGUEDAS, 2015 e VALLE, 2006).

Assim, as transformações socioespaciais do território quilombola de Acauã tem nas obras de construção da barragem Engenheiro José Batista do Rego Pereira, conhecida também como açude Poço Branco, iniciada em meados de 1959, mas já idealizada desde 1950, o evento de maior impacto no cotidiano dos moradores. Em 1959, engenheiros da firma Nóbrega Machado deram início às obras de construção da barragem após aprovação do projeto pelas autoridades municipais utilizando recursos federais através do Departamento de Obras e Saneamento (Dnocs). As obras tiveram início em 1959 e foram concluídas em 1968 (Figura 1), pouco depois da emancipação política do município de Poço Branco em 1963, até então pertencente ao município de Taipu (VALLE, 2006).

Figura 1: Barragem Engenheiro José Batista do Rego Pereira (Açude Poço Branco) no município de Poço Branco - RN, Brasil

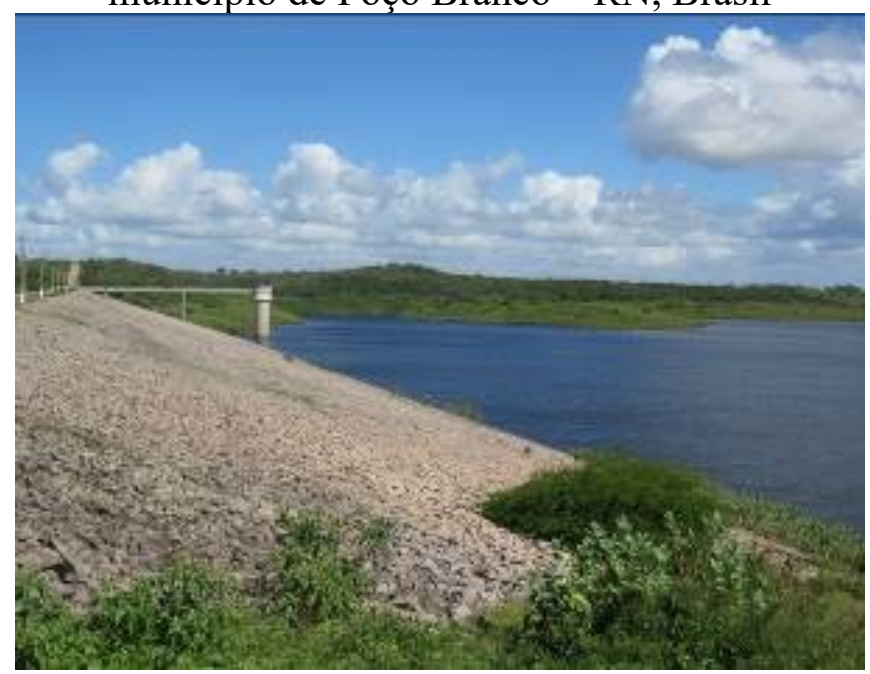

Fonte: Pereira (2018). 
Com a construção da barragem, o rio Ceará-Mirim teve seu nível aumentado, significativamente, ocasionando o projeto de realocação das famílias que viviam às margens do rio, como os povoados denominados de Contador e a antiga comunidade de Acauã (Cunhã Velha). Conforme Arguedas (2015) além dessas, outras localidades foram atingidas pela construção da barragem como a chamada Vila de Poço Branco que deu lugar à sede do município. O autor acrescenta que "quando o nível das águas do açude está baixo, durante a época seca, é possível ver algumas velhas estruturas da antiga Poço Branco, com o destaque da igreja (ARGUEDAS, 2015, p. 64).

Valle (2006) evidencia que não houve preocupação dos órgãos competentes com a situação das populações ribeirinhas. Segundo o autor "parece não ter havido um projeto específico de deslocamento populacional que considerasse os fatores socioculturais e econômicos das famílias atingidas pela barragem nem as consequências da mudança social, ao menos, a médio e longo prazo" (VALLE, 2006, p. 70). No novo local de alocação dos moradores de Acauã era inviável a produção econômica para além do cultivo de hortaliças e algumas árvores frutíferas em virtude das dificuldades de acesso a água do reservatório, que também ocasionou a perda de áreas de plantio antes cultivados nas proximidades do açude.

A saída involuntária dos moradores da Cunhã Velha para a construção de um "novo" território, Acauã, ocasionou fragmentações nas relações entre os moradores da Cunhã Velha que se viram obrigados a decidirem seus destinos, mas também fortaleceu a organização de uma parte deles que exigiram continuar nas proximidades da barragem.

A construção da barragem ocasionou mudanças nas dinâmicas territoriais da comunidade em seus conteúdos cultural, produtivo e político-organizacional. Pensar a desterritorialização unicamente como a saída voluntária e involuntária de indivíduos ou grupos sociais de um determinado local omite os processos que sequenciam esse deslocamento. Movimentar-se, ainda que compulsoriamente, dentro de uma rede de relações que produzem o território, não condiciona a eliminação das identidades e territorialidades dos grupos sociais, mas as ressignifica, fragmentando os sentimentos de pertença dos grupos ou fortalecendo-os diante das tensões que impulsionaram seu deslocamento (HAESBAERT, 2005). 
As transformações sociais e territoriais pelas quais os moradores da Cunhã Velha passaram a enfrentar, os inseriu em uma dinâmica de uso do território diferente daquela de costume nas antigas terras em que ocupavam, pois ao mesmo tempo que permitiu maior aproximação dos moradores ao centro da cidade de Poço Branco, fragilizou as territorialidades do grupo e produziu outras, a partir da ampliação das redes de sociabilidades desses grupos.

Além de as ações de indenização terem coberto somente o valor das casas ocupadas e desconsiderarem as áreas de plantio e o valor dos lotes, retirando dos moradores o direito do valor real de seus imóveis (VALLE, 2006), a cidade cresceu em população, após a construção da barragem, e algumas disputas se produziram no campo, inclusive em Acauã. Um problema que a ex-liderança quilombola relata, foi a invasão das terras por pessoas atraídas pelo seu valor capital adquirido e as limitações dos moradores à água da barragem e à terra, que mesmo com as restrições, passaram a sobreviver de serviços temporários e da agricultura familiar. Com a construção da barragem e o pagamento de algumas indenizações de maneira irregular somente dezesseis das trinta famílias conseguiram ficar morando nas novas terras de Acauã (VALLE, 2006).

Inicialmente, os moradores que migraram das terras da Cunhã Velha para Acauã, como passou a ser chamada, viviam em 4 hectares de terra adquiridos através das negociações com a prefeitura e a pelo pagamento com o valor das indenizações. As 47 famílias $^{6}$ esperavam que o total de 540,51 hectares, incluindo 159,54 onde a comunidade se concentra, fossem desapropriados para a titulação, mas devido a alguns arranjos burocráticos articulados por proprietários de terras, a comunidade perdeu 201,69 hectares da Fazenda Maringá e espera que sejam finalizados e entregues os títulos dos 338,72 hectares restantes ${ }^{7}$, conforme apresentamos no Quadro 1 produzido a partir de pesquisa documental feita no Incra - RN.

\footnotetext{
${ }^{6}$ No relatório antropológico elaborado por Valle (2006) há 56 famílias, mas dados do Incra de 2014 apontam 47.

${ }^{7}$ Conforme Portaria No 91, de 19 de março de 2008 (INCRA - MDA).
} 
Quadro 1: Situação atual das terras da comunidade quilombola Acauã, Poço Branco

(RN)

\begin{tabular}{|c|c|c|c|c|}
\hline $\begin{array}{l}\text { NOME DO } \\
\text { IMÓVEL }\end{array}$ & $\begin{array}{l}\text { NOME DO EX } \\
\text { PROPRIETÁRIO }\end{array}$ & $\begin{array}{l}\text { ÁREA } \\
\text { (HA) }\end{array}$ & $\begin{array}{l}\text { VALOR TOTAL } \\
\text { DO IMÓVEL }\end{array}$ & SITUAÇÃO \\
\hline Sítio São Sebastião & $\begin{array}{l}\text { Belchior de Oliveira } \\
\text { Rocha }\end{array}$ & 15,5385 & $21.840,32$ & Indenizado \\
\hline Fazenda Amarelona & $\begin{array}{lll}\text { Antonio Soares da } \\
\text { Rocha }\end{array}$ & 179,2824 & $152.646,11$ & $\begin{array}{l}\text { Indenizado } \\
\text { CCDRU }\end{array}$ \\
\hline Fazenda Gamellare & Heriberto José Turra & 47,9258 & $29.154,54$ & $\begin{array}{l}\text { Indenizado } \\
\text { CCDRU }\end{array}$ \\
\hline $\begin{array}{lll}\text { Sítio } & \text { São } & \text { Luiz } \\
(\text { Posse) } & & \end{array}$ & $\begin{array}{l}\text { Manoel Ferreira da } \\
\text { Cruz Irmão }\end{array}$ & 27,6824 & $27.750,80$ & $\begin{array}{l}\text { Avaliado } \\
\text { (POSSE) }\end{array}$ \\
\hline $\begin{array}{ll}\text { Fazenda } \\
\text { Esperança }\end{array}$ & $\begin{array}{|ll|}\begin{array}{l}\text { Helione Justino de } \\
\text { Freitas }\end{array} & \\
\end{array}$ & 38,961 & $54.634,97$ & $\begin{array}{l}\text { Indenizado } \\
\text { CCDRU }\end{array}$ \\
\hline Santa Terezinha & $\begin{array}{lll}\text { Severino } & \text { Tomás } & \text { de } \\
\text { Carvalho } & & \end{array}$ & 22,00 & $52.878,66$ & $\begin{array}{l}\text { Mandado } \\
\text { Translativo } \\
(02 / 2017)\end{array}$ \\
\hline Fazenda Maringá & $\begin{array}{l}\text { Elias Azevedo da } \\
\text { Cunha Filho }\end{array}$ & 201,6916 & ------------ & $\begin{array}{l}\text { Ação perdida } \\
\text { no STF }\end{array}$ \\
\hline
\end{tabular}

Fonte: Pesquisa documental - Incra (2018).

Os imóveis indenizados com ou sem Concessão de Direito Real de Uso (CCDRU) já não estão mais sob ação judicial e já vêm sendo utilizados pelos moradores desde 2013, mesmo ainda não titulados e sob posse do Incra. A Fazenda Santa Terezinha, na qual aparece o mandado translativo, está definida a desapropriação e o valor a ser pago, sendo feita a transferência definitiva de titularidade somente após julgamento de ação judicial, na qual os proprietários podem pedir revisão de valor. $\mathrm{O}$ Sítio São Luiz é área de posseiro e o processo tramita sem perspectiva de data para desintegração de posse. A desapropriação da Fazenda Boa Esperança ainda não teve o valor pago e sobre a Fazenda Maringá o proprietário teve ganho de causa. Os dois últimos imóveis foram alvos de ações conflituosas com a comunidade e daremos destaque na sequência.

A expressão que inicia esse item "Mexeu com uma, mexeu com todas" foi proferida por uma moradora da comunidade de Acauã durante a audiência em defesa dos direitos dos povos quilombolas, realizada em 9 de junho de 2017. A ADI já representava uma ameaça aos direitos quilombolas, mas desde 2008, essa comunidade vivenciava problemas com os proprietários da região. Dois processos foram abertos, no 
referido ano, pelos proprietários das Fazendas Maringá e Boa Esperança contra a desapropriação dos imóveis.

De acordo com Arguedas (2015) em 2008, o proprietário da Fazenda Maringá, juntamente com os proprietários do Sítio São Luiz e da Fazenda Boa Esperança, entrou com um processo na Justiça Federal do Rio Grande do Norte para a anulação do processo de titulação do território de Acauã, alegando a inexistência de fatos históricos comprováveis dessa identidade. O processo aberto reivindicava o direito a 201,69 hectares de terras localizados na margem direita da barragem onde a comunidade não está concentrada, mas possui glebas de terras, ficou parado por tempo indeterminado, interditando o uso das terras por ambas as partes, sendo reaberto no STF, anos depois e dando parecer favorável para o proprietário da Fazenda Maringá, em 2018. A decisão do STF tramitou sem que a comunidade fosse comunicada para que pudesse intervir e foi desfavorável à comunidade que perdeu parte dos 540 hectares previstos para fins de titulação da comunidade.

O outro conflito travado pela comunidade, iniciado também em 2008, foi acionado pelos proprietários da Fazenda Boa Esperança. Neste mesmo ano, foi decretada a desapropriação de parte das terras que a comunidade alegava como suas. A indenização prevista era de $\mathrm{R} \$ 54.634,97$, mas os proprietários exigiram a quantia de $\mathrm{R} \$ 184.909,60$. O juiz, porém acrescentou $\mathrm{R} \$ 3.000,00$ ao valor estipulado inicialmente $^{8}$, mas mesmo assim recorreram da decisão ao Tribunal Regional Federal da $5^{\mathrm{a}}$ região em Recife $(\mathrm{PE})$ alegando que, estando para ser votada a $\mathrm{ADI}$, a decisão judicial necessita ser revista. Foi nesse contexto que a audiência em defesa dos direitos de Acauã mobilizou comunidades de todo o estado

Arguedas (2015) destaca que, após a publicação do Relatório Técnico de Identificação e Delimitação (RTID) do território de Acauã, em 2005, um incêndio em alguns barracos da comunidade (Figura 2), além de invasão de gado das fazendas às áreas de plantio dos quilombolas e a proibição da circulação das famílias pelas terras foram alguns dos conflitos no território após o início do processo de titulação da comunidade.

\footnotetext{
${ }^{8}$ Valores informados no site da Coordenação Nacional de Articulação das Comunidades Negras Rurais Quilombolas - CONAQ (2017).
} 
Figura 2: Incêndio nas terras da comunidade quilombola Acauã, Poço Branco - RN, Brasil

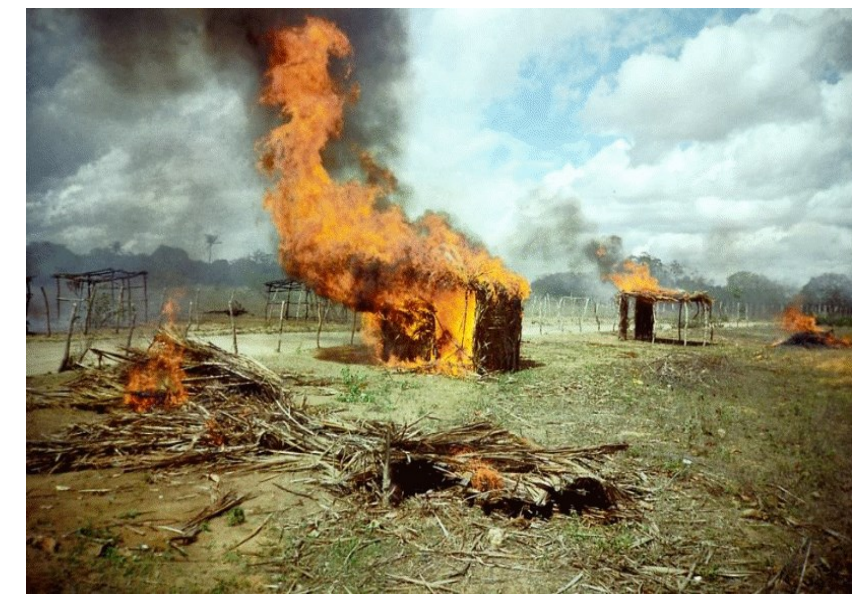

Fonte: Arguedas (2015). Foto cedida por Jair Ferreira de Souza

A imbricação de relações políticas, culturais, econômicas e institucionais, revelam que a reterritorialização dos quilombolas de Acauã mesclou-se também à entrada de outros agentes territoriais por mediação do Estado e as relações divergentes de uso e valores do território, ocasionaram as disparidades que nele se materializaram (HAESBAERT, 2010).

A revisão do processo da Fazenda Boa Esperança contra a indenização prevista para Acauã seria julgada no dia 21 de junho de 2017 pelo Tribunal Federal Regional da $5^{\mathrm{a}}$ Região em Recife (PE), mas foi retirado de pauta no dia da audiência de julgamento, ficando sem nova data prevista. No entanto, após a reprovação da ADI, o processo contra Acauã foi encerrado sendo favorável à comunidade que aguarda a finalização dos trâmites da desapropriação dos 38,961 hectares referentes à antiga fazenda.

Ainda assim, o direito principal das comunidades quilombolas ainda não está totalmente assegurado, uma vez que as comunidades quilombolas passaram a enfrentar um cenário de instabilidade sobre como tramitarão as ações de titulação que antes era atribuição do Incra. Para o entendimento da organização do território de Acauã, o Mapa 1, apresenta as estruturas, as áreas de conflito e os espaços de socialização na comunidade. 
Mapa 1: Organização do território quilombola Acauã, Poço Branco - RN, Brasil

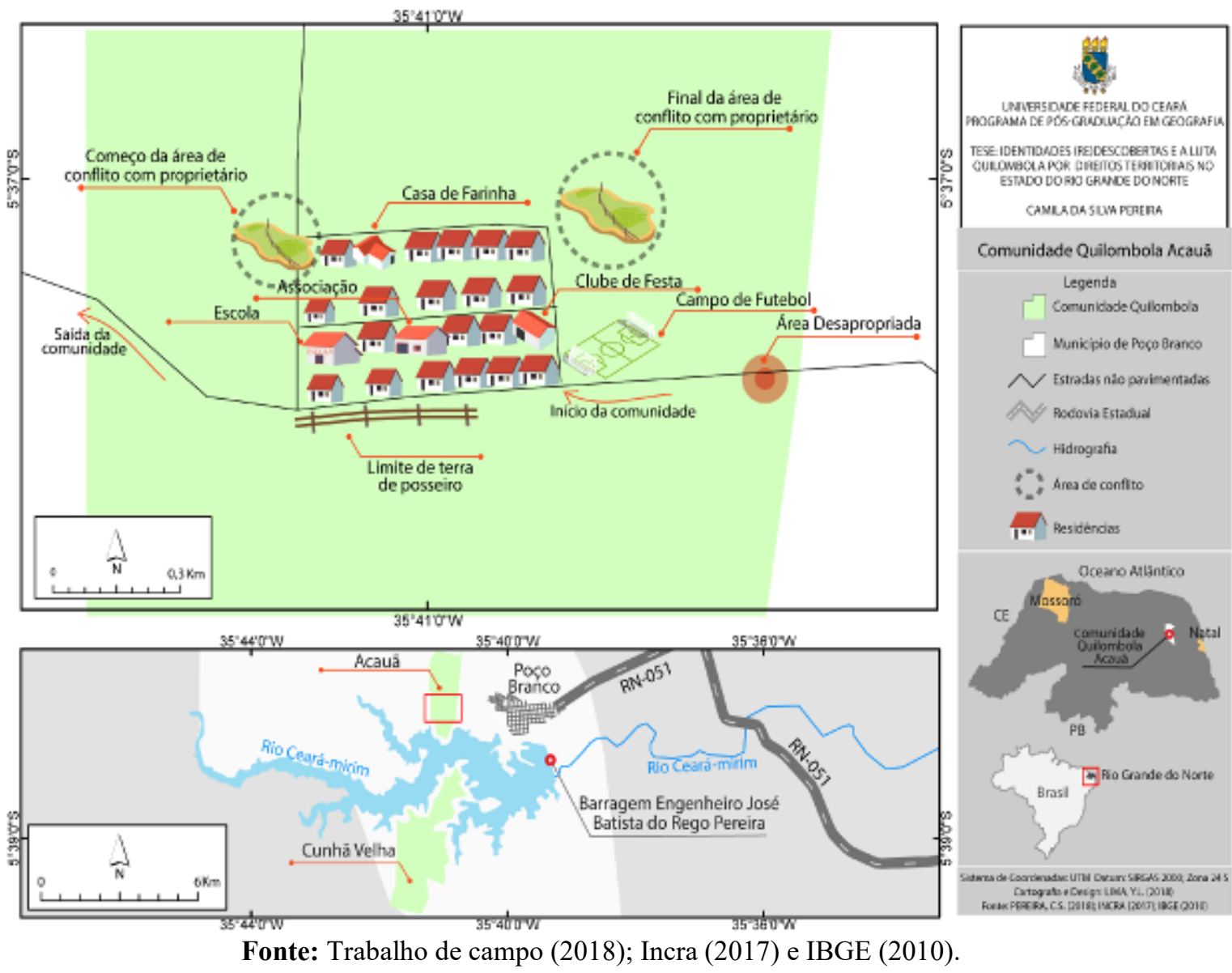

No Mapa 1, há destaque para a barragem de Poço Branco. Ao sul temos a antiga comunidade Cunhã Velha aonde a comunidade residia antes da construção da barragem e ao norte a comunidade de Acauã onde os moradores atualmente moram. A área destacada como "começo da área de conflito" e "final da área de conflito" abrange o imóvel da antiga Fazenda Boa Esperança. Fato que chama a atenção é que na extensão das terras da Fazenda Boa Esperança já existiam estruturas da comunidade incluindo residências e a casa de farinha (Figura 3), que inclusive encontra-se desativada devido à estiagem dos últimos seis anos que vem dificultando o plantio e, consequentemente, o processamento da mandioca.

A área destacada, no mapa como "limite de posseiro" corresponde ao Sítio São Luiz que ainda está com processo em tramitação para fins de desapropriação (Figura 4). A zona marcada como desapropriada corresponde ao Sítio São Sebastião que já teve processo de desapropriação encerrado. 
Figura 3: Casa de farinha da comunidade quilombola Acauã, Poço Branco - RN, Brasil

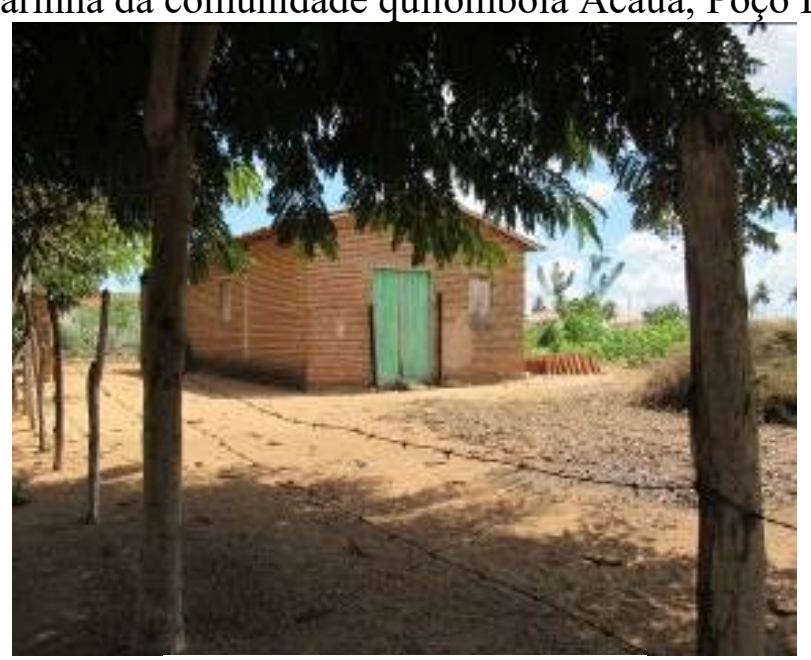

Fonte: Trabalho de campo (2018).

Figura 4: Área de posseiro na comunidade quilombola Acauã, Poço Branco - RN, Brasil

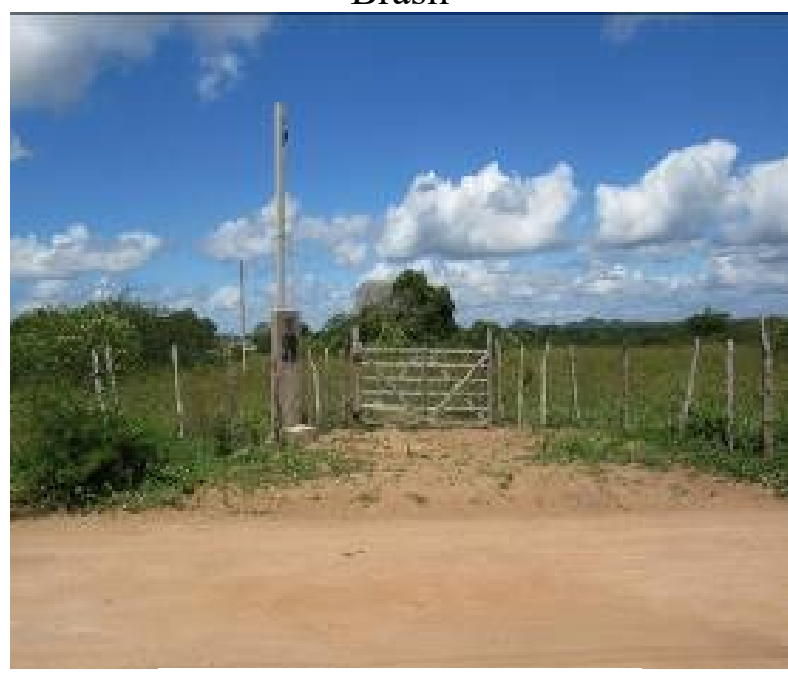

Fonte: Trabalho de campo (2018).

Os espaços de socialização da comunidade são a Associação dos Moradores do Quilombo de Acauã - AMQA (Figura 5), onde ocorrem reuniões, eventos e atendimentos médicos quinzenais, uma vez que na comunidade não há posto de saúde; a Escola Municipal de Ensino Infantil da comunidade (Figura 6); uma capela em construção destinada às celebrações e festejos religiosos, majoritariamente, católicos; um clube de festa que funciona como ponto de encontro dos moradores em datas comemorativas e um campo de futebol. 
Figura 5: Associação dos Moradores do Quilombo de Acauã (AMQA)

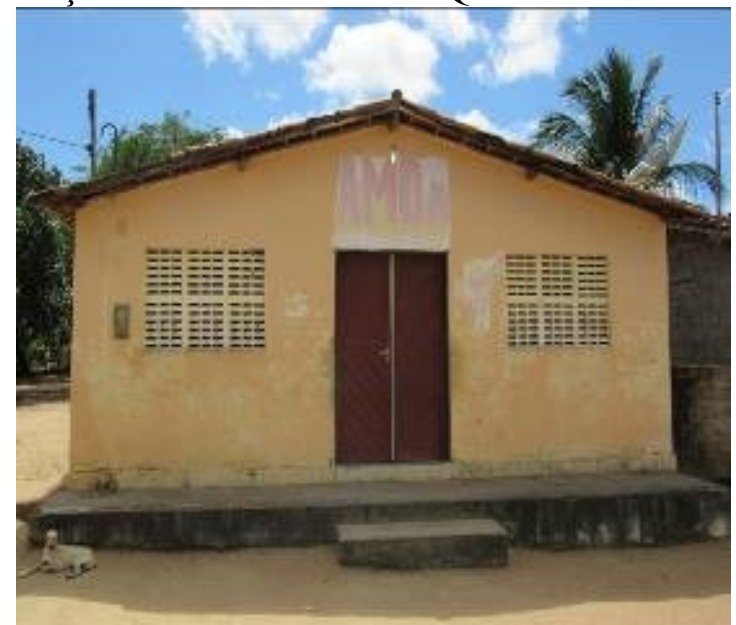

Fonte: Trabalho de campo (2018).

Figura 6: Escola Municipal de Ensino Infantil da comunidade Acauã, Poço Branco $\mathrm{RN}$, Brasil

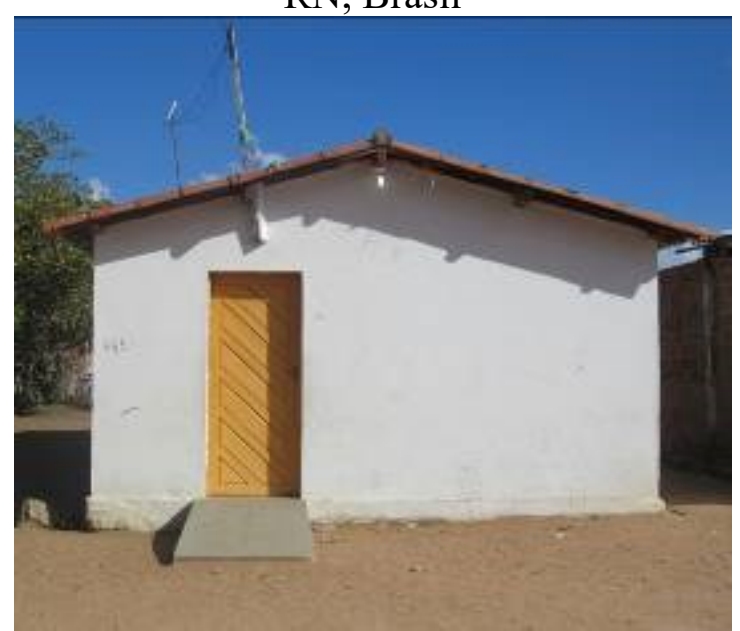

Fonte: Trabalho de campo (2018).

Há apenas uma sala de aula para alunos de variados níveis de aprendizagem e faixas etárias diversificadas e a escola atende crianças até os 7 anos de idade. Os recursos são escassos e, de acordo com a professora, há um risco de a escola parar de funcionar nos próximos dois anos, tendo em vista a diminuição progressiva da quantidade de alunos e que, segundo a prefeitura, há transporte e condições de os alunos serem deslocados até Poço Branco para estudarem. Essa alegação omite a importância de os alunos terem, nos anos iniciais, uma educação minimamente contextualizada, embora a professora da escola, moradora da comunidade, reconheça as dificuldades dessa forma de educar, pois ainda há muito preconceito dos moradores da cidade com os quilombolas de Acauã. 
As áreas de residência e plantio da comunidade têm se expandido nos últimos anos após a emissão de contratos de concessão de uso que permitem a comunidade utilizar as terras já desapropriadas, embora ainda não tituladas. Algumas das culturas produzidas na comunidade são o milho, o feijão, a mandioca e árvores frutíferas como banana e manga nas áreas próximas às residências (Figura 7). $\mathrm{O}$ abastecimento da comunidade ocorre por meio da barragem, além de todas as residências contam com cisternas para o armazenamento de água destinada, principalmente, para as atividades domésticas e para o consumo humano. Além de uma cisterna de enxurrada utilizada para armazenar água para o consumo animal e para irrigação (Figura 8).

Figura 7: Plantio de banana no quintal dos moradores da comunidade quilombola Acauã, Poço Branco - RN, Brasil

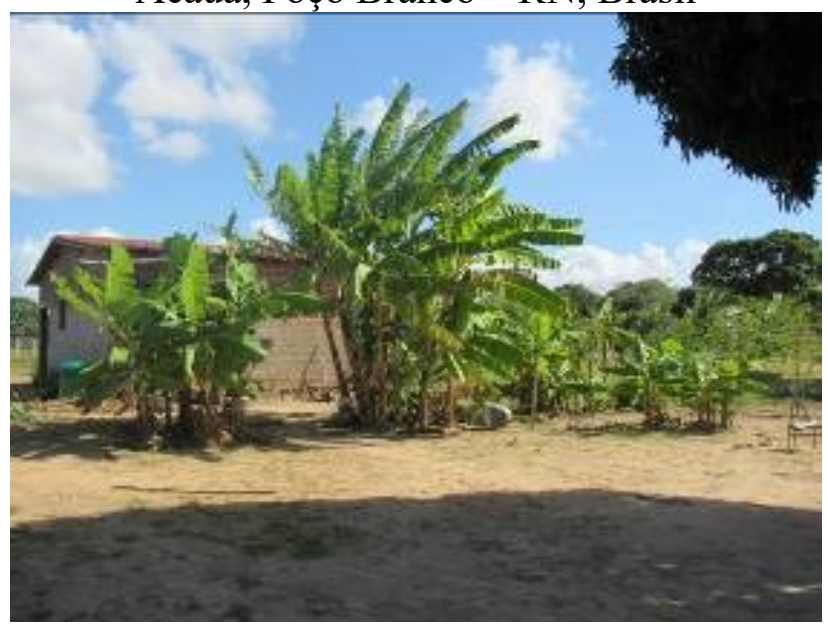

Fonte: Trabalho de campo (2018).

Figura 8: Cisterna de enxurrada na comunidade quilombola Acauã, Poço Branco RN, Brasil

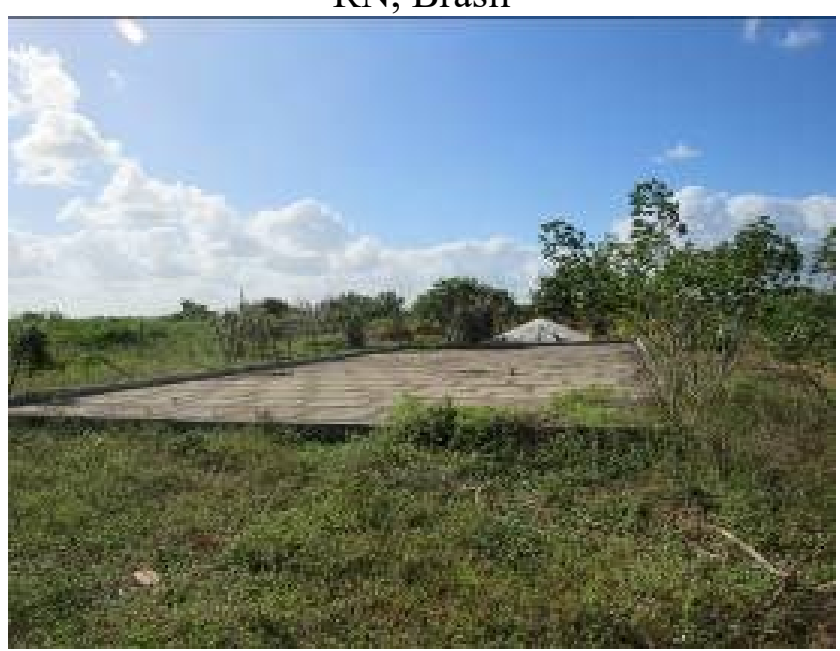

Fonte: Trabalho de campo (2018). 
Além da agricultura familiar, as fontes de renda dos moradores de Acauã se baseiam no Programa Bolsa Família, benefícios de prestação continuada (aposentadorias a idosos ou pessoa com deficiência física ou mental) e trabalhos informais de pedreiro, empregadas domésticas, entre outros.

A comunidade, que conta com processo de titulação em estágio bastante avançado ainda enfrenta os arranjos burocráticos institucionais e resistências de agentes territoriais contrários à efetivação do seu direito à terra. Essas inseguranças não são singulares a Acauã, engloba todas as comunidades que veem, de maneira recorrente, seus direitos básicos sendo burlados modificando as suas formas de viver o território e de nele resistir.

\section{Considerações finais}

Tem ocorrido, nas últimas décadas, o aprofundamento dos debates acerca da diversidade da formação das comunidades quilombolas em todo o Brasil, permitindo que a origem das suas territorializações seja compreendida para além da ideia unilateral dos processos de fuga. Isso deu-se, também em virtude do surgimento de movimentos importantes para o protagonismo das demandas dessas populações no cenário legislativo, o mais expressivo foi o Movimento Negro Unificado no final da década de 1970.

Com o reconhecimento do seu principal direito, a terra, na Constituição Federal de 1988, as comunidades quilombolas vieram ao longo dos últimos anos, travando lutas com agentes territoriais e políticos que desenvolvem novas estratégias para deslegitimar direitos assegurados por lei, algumas destas são: a ADI 3.239/2004, a extinção do MDA, a retirada e a transferência de funções de órgãos específicos para lidar com as ações de titulação e o obscurantismo que se instaurou no último ano sobre o destino das políticas sociais que contribuem na manutenção físico-social dos territórios quilombolas.

O estudo realizado sobre a comunidade Acauã demonstra os impactos do uso de algumas dessas estratégias que culminaram na restrição do uso de água da barragem de Poço Branco para as atividades cotidianas na comunidade, na perda de mais de 200 hectares de terras no processo movido pelo proprietário da Fazenda Maringá, bem como 
no risco de serem retirados de outra porção onde já haviam estruturas físicas, caso o processo da Fazenda Boa Esperança tivesse sido votado antes da decisão sobre a ADI, além de no cenário atual, o seu processo de titulação estar estancado, assim como de outras comunidades, após a MP 870/2019.

Diante disso, a comunidade que, no trâmite do seu processo de titulação detinha direito a um total de 540,51 hectares, incluindo as terras aonde as famílias estão situadas, bem como as propriedades vizinhas e áreas de posseiros, perdeu 201,69 referente a ação, acima mencionada, restando em torno de 338,72 hectares a serem titulados.

Discutir a luta quilombola no cenário potiguar, a partir do exemplo de Acauã, permite entender que as referências desse processo são escassas ou inexistentes, o que ocasionou o enfraquecimento dos grupos pelas dificuldades de se reconhecerem na história e, por conseguinte, colocou-os em situação vulnerável para a perda de suas terras e demais direitos. A luta quilombola configura uma constante e complexa maneira de resistir cotidianamente às investidas do capital, à burocratização das ações do Estado e à fragmentação dos seus processos de identificação.

Nesse processo de resistência, a terra, elemento comum a todas as comunidades e necessária para a reprodução econômica e social dos grupos, tem significado político, cultural e ambiental. Embora o território transcenda a noção de terra, ela é, para as comunidades quilombolas, a condição fundamental para a garantia mínima da manutenção das relações de produção. No entanto, somente a terra não garante todos os meios para a continuidade das práticas sociais em sentido amplo, mas sem ela o território perde o referencial comum de convergência dos grupos, visto que o seu significado é ancestral e histórico e não somente material.

O histórico de lutas dos quilombolas de Acauã frente às formas de exploração na terra e diante das estratégias de privá-los de seu direito principal e básico para a sobrevivência, expressa a realidade de muitas outras comunidades quilombolas do Brasil que estão em área de expansão do capital e que embora tenham assegurados legalmente seus direitos, estes não são garantidos pelas investidas dos agentes capitalistas no espaço e pela burocracia das ações por parte do Estado. 


\section{AGRADECIMENTOS}

À comunidade quilombola Acauã pela parceria na construção da pesquisa de doutorado que gerou esse trabalho.

\section{REFERÊNCIAS}

ALMEIDA, Alfredo Wagner Berno de. Quilombos e as novas etnias. Manaus: UEA Edições, 2011.

ARGUEDAS, Alberto Gutiérrez. Território para viver: dinâmicas territoriais da comunidade quilombola de Acauã. 2015. 200 f. Dissertação (Mestrado em Geografia) Universidade Federal do Rio Grande do Norte, Natal, 2015.

BOSI, Ecléa. O tempo vivo da memória: ensaios de psicologia social. São Paulo: Ateliê Editorial, 2003.

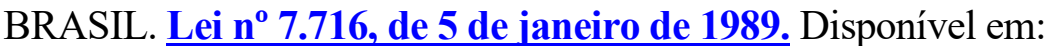
http://www.planalto.gov.br/ccivil 03/LEIS/L7716.htm. Acesso em: 16 jun. 2017.

BRASIL. Lei $\mathbf{n}^{\mathbf{0}}$ 7.437, de 20 de dezembro de 1985. Disponível em: http://www.planalto.gov.br/ccivil 03/LEIS/L7437.htm. Acesso em: 15 jun. 2017.

BRASIL. STF garante posse de terras às comunidades quilombolas, 2018. Disponível em: http://www.stf.jus.br/portal/cms/verNoticiaDetalhe.asp?idConteudo=369187. Acesso em: 25 abr. 2018.

CHALHOUB, Sidney. Machado de Assis: historiador. São Paulo: Companhia das Letras, 2003.

CONAC - Coordenação Nacional de Articulação das Comunidades Negras Rurais Quilombolas. Ação judicial no RN retira direitos de quilombolas em todo o país. Disponível em: http://conaq.org.br/noticias/acao-judicial-no-rn-retira-direitos-dequilombolas-em-todo-o-pais/. Acesso em: 26 jun. 2017.

CPISP - Comissão Pró-índio de São Paulo. Terras Quilombolas - Adiado mais uma vez o julgamento da ADI 3239, 2015. Disponível em: http://cpisp.org.br/terras-quilombolasadiado-mais-uma-vez-o-julgamento-da-adi-3239/. Acesso em: $10 \mathrm{dez} .2017$.

DIAMANTINO, Pedro Teixeira. Numa canetada, o recuo de 15 anos na política de terras quilombolas. Jornal Carta Capital, São Paulo, 17 mai. 2016. Disponível em: https://www.cartacapital.com.br/sociedade/numa-canetada-o-recuo-de-15-anos-na-politicade-terras-quilombolas . Acesso em: 20 jun. 2017.

FERNANDES Bernardo Mançano; COCA, Estevan Leopoldo de Freitas; VINHA, Janaina Francisca de Souza Campos; CLEPS JÚNIOR, João; DANTAS, José Carlos; SOBREIRO 
FILHO, José. A questão agrária na segunda fase neoliberal no Brasil. Boletim da Luta, Presidente Prudente, v. 1, n. 109, p. 1-16, janeiro, 2017.

FERNANDES, Florestan. A integração do negro na sociedade de classes: o legado da raça branca. 5. ed. São Paulo: Globo, 2008.

FIABANI, Adelmir. Os novos quilombos: luta pela terra e afirmação étnica no Brasil (1988 - 2008). 2008. 275 f. Tese (Doutorado em História) - Universidade do Vale do Rio dos Sinos - Unisinos, 2008.

GOMES, Flávio dos Santos. Mocambos e quilombos: uma história do campesinato negro no Brasil. 1. ed. São Paulo: Claro Enigma, 2015.

GONÇALVES, Juliana. STF adia, pela terceira vez, julgamento que define titulação de quilombos Brasil de Fato, São Paulo, 19 out. 2017. Disponível em:

https://www.brasildefato.com.br/2017/10/19/stf-adia-pela-terceira-vez-julgamento-quedefine-titulacao-de-quilombos/. Acesso em: 25 jan. 2018.

HAESBAERT, Rogério. Regional global: dilemas da região e da regionalização na geografia contemporânea. Rio de Janeiro: Bertrand Brasil, 2010.

HAESBAERT, Rogério. Da desterritorialização à multiterritorialidade. In: ENCONTRO DE GEÓGRAFOS DA AMÉRICA LATINA. 10. 2005, São Paulo. Anais [...]. São Paulo: EGAL, 2005. p. $6774-6792$.

MDA - Ministério do Desenvolvimento Agrário. Os 60 territórios da cidadania. Disponível em: http://www.mda.gov.br/sitemda/sites/sitemda/files/ceazinepdf/3697596.pdf. Acesso em: 20 ago. 2018.

MDA - Ministério do Desenvolvimento Agrário. Territórios da cidadania: integração de políticas públicas para reduzir desigualdades. 2009. Disponível em: http://www.mda.gov.br/sitemda/sites/sitemda/files/ceazinepdf/3638134.pdf. Acesso em: 25 nov. 2018.

PEREIRA, Amauri Mendes. Trajetória e perspectivas do Movimento Negro Brasileiro. 1 ed. Belo Horizonte: Nandyala, 2008.

PEREIRA, Camila da Silva. Identidades (re)descobertas e a luta quilombola por direitos territoriais no estado do Rio Grande do Norte, Brasil. 2019. 291 f. Tese (Doutorado) - Universidade Federal do Ceará, Fortaleza, 2019. https://doi.org/10.5216/ag.v13i1.52604

VALLE, Carlos Guilherme Octaviano do. A comunidade quilombola de Acauã Cunhã, Cunhã Velha, Rio Grande do Norte. Relatório antropológico de Acauã. Convênio UFRN/Incra - RN. Natal, 2006.

WOORTMANN, Ellen. Herdeiros, parentes e compadres. Brasília: Hucitec - Editora Universidade de Brasília, 1995. 
A luta por terra e água no quilombo de Acauã no Rio Grande do Norte, Brasil

Camila da Silva Pereira 